\title{
Decentralized Control of PV Inverter to Mitigate Voltage Rise in Resistive Feeder
}

\author{
Tzung-Lin Lee ${ }^{1 *}$, Shang-Hung Hu ${ }^{1}$, and Shih-Sian Yang ${ }^{1}$ \\ ${ }^{1}$ Department of Electrical Engineering National Sun Yat-sen University TAIWAN
}

\begin{abstract}
Increasing installation of photovoltaic (PV) in the distribution power system has resulted in serious voltage rise, limiting grid-connectable power. This scenario becomes significant in the low-voltage resistive feeder. This paper proposes a decentralized control for distributed PV inverters to mitigate voltage rise. Instead of MPPT (maximum power point tracking) mode, the proposed PV inverter is able to curtail its real power and compensate the reactive power according to the impedance at the installation location. The drooped characteristics between the output power and the impedance are developed so that the PV inverters are able to cooperatively suppress voltage rise based on their local voltage measurement only. Therefore, PV inverters are allowed to supply more power to the utility within voltage limitation. Simulations are conducted to guarantee the proposed control on improvement of voltage rise considering different parameter of feeder. A lab-scaled prototype circuit is established to verify effectiveness in a resistive feeder.
\end{abstract}

\section{Introduction}

Renewable energy sources have received much attention due to environmental concerns and shortage of fossil fuel. Power electronics-based photovoltaic (PV) inverter is becoming popular with continuing cost down and government support. However, intermittent characteristic of $\mathrm{PV}$ generation results in rapid variation of voltage, thus deteriorating power quality [1]-[2]. In order to assure security, various grid codes have defined operational conditions for grid-connected renewable energy sources. In VDE 0126-1-1 [3] and IEC 61727 [4], PV inverters should stay at grid-connected mode within $110 \% \sim 85 \%$ nominal voltage. As grid voltage is not inside the normal operation range, PV inverters must stop their output for security reasons. In Taiwan, grid voltage is strictly limited in the range of 95\% 105\% nominal value by Taiwan Power Company (Taipower) [5]. Thus installation of PV inverters might be seriously limited toward the end of the feeder.

In the conventional power system, on-line tap changer (OLTC), line voltage drop compensator (LDC) or switching capacitor/reactor has been used to regulate grid voltage to avoid variation due to load change. However, these methods may not be suitable for high penetration of PV system since PV generation is intermittent and varies with environmental conditions, such as radiation and temperature. Power quality compensators, such as static synchronous compensator (STATCOM) and unified power flow controller (UPFC), have been presented to improve power quality in recently years [6]-[12]. Typically these compensators are designed to improve voltage fluctuation at their installation location. Voltage rise may still be significant on the feeder with no compensator installed. Most importantly, they suffer from extra expenses in terms of installation cost and operating loss. In [13]-[18], PV inverter was proposed to operate in non-unity power factor to compensate reactive power locally. In this way, voltage rise can be alleviated by PV inverter itself. In [18], PV inverter can flexibly adjust the injected reactive power to mitigate voltage rise based on the impedance at its installation point. The voltage rise can be suppressed in the condition of the inductive feeder, but the improvement is not clear in the feeder with high $\mathrm{R} / \mathrm{X}$ ratio. In this case, the reactive power needed to mitigate voltage rise is so large as to increase conducting losses in the feeder. In [19], PV inverters with built-in active power curtailment (APC) were presented to suppress voltage rise. However, its effectiveness might not be clear since the droop algorithm of APC does not consider the impact of line impedance, especially in the resistive feeder.

The authors have presented a decentralized control for dispersed PV inverters to cooperatively alleviate voltage rise in the distribution system [20]. Deviating from MPPT (maximum power point tracking) operation, the proposed PV inverter is able to curtail its real power and compensate reactive power according to the resistive and inductive characteristics of the impedance at the installation location, respectively. Therefore, various PV inverters are able to cooperatively maintain the feeder voltage in an acceptable level to allow more power being delivered to utility. Preliminary simulations have been conducted in [20]. In this paper, power-flow analysis and full simulations are provided considering various $\mathrm{R} / \mathrm{X}$ ratio of the feeder. Two inverters in a resistive feeder are

Corresponding author: tllee@mail.ee.nsysu.edu.tw 
established to verify effectiveness of the proposed control.

\section{OPERATION PRINCIPLE}

Fig. 1a illustrates the studied PV generation system, in which three PV inverters PV1, PV2, PV3 are considered. The inverters are installed at different location separated by line impedance $\mathrm{ZLi}=\mathrm{RLi}+\mathrm{XLi}$ (i=1, 2, 3). PV system typically consists of two-stage power conversion (DC/DC converter and DC/AC inverter) in cascaded connection. DC/DC converter is responsible for the MPPT control, while DC/AC inverter is intended for grid-connected operation. In this paper, we assume the output of DC/DC converter is a stiff voltage source to simplify the studied voltage control of DC/AC inverter. Fig. 1b shows the proposed control block diagram of PVi inverter where the subscript i represents the inverter index. As can be seen, the decentralized control of the PV inverter determines the real power command $\mathrm{Pi}^{*}$ and the reactive power command $\mathrm{Qi}^{*}$ according to voltage measurement at installation location. Since the decentralized control works in a drooped manner, all PV inverters are able to cooperatively suppress voltage rise along the entire feeder with no communication required. The detailed control is explained in the following sections.

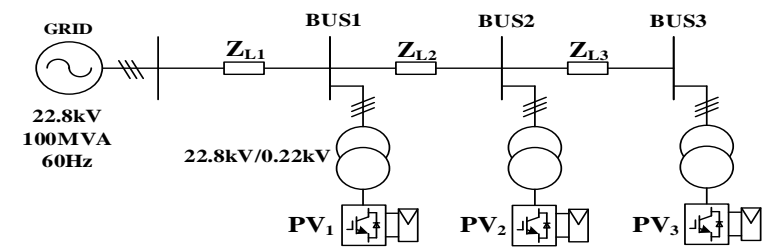

(a)

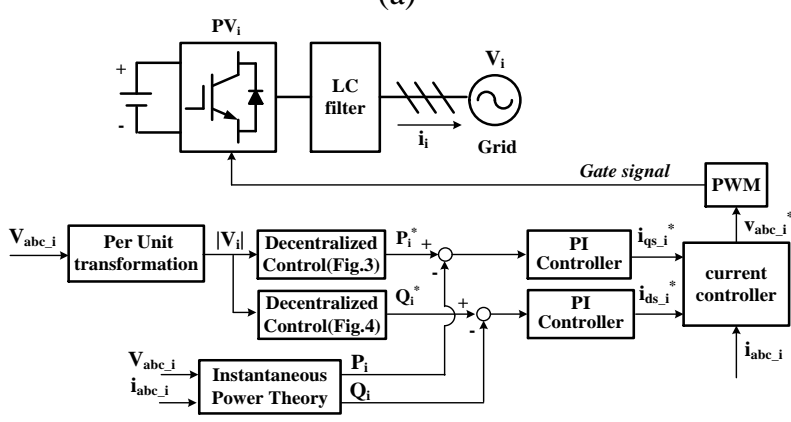

(b)

Fig. 1. The considered PV generation system and control block diagram

(a). PV generation system

(b). control block diagram of $\mathrm{PV}_{\mathrm{i}}$

\section{A. Decentralized control}

Reverse power flow contributed by distributed PV inverters results in voltage fluctuation. According to sensitivity analysis [17], voltage magnitude is related to the real power in a resistive feeder, but dependent on the reactive power in an inductive feeder. In this paper, the inverter is proposed to adjust both real power and reactive power to alleviate voltage rise based on voltage magnitude at its installation point. Fig. 2a shows the curtailing strategy to determine $\mathrm{Pi}^{*}$. The inverter normally operates at the MPPT mode outputting real power PMPPT_i. When $|\mathrm{Vi}|$ is larger than $1+\mathrm{DPi}, \mathrm{Pi}^{*}$ decreases with increasing $|\mathrm{Vi}|$. DPi is defined as a turndown point to start shortening real power. The inverter stops output of real power after $|\mathrm{Vi}|$ exceeds the upper limit of the feeder voltage VOP. Fig. $2 b$ shows the compensating scheme of reactive power. The inverter starts to compensate reactive power as $|\mathrm{Vi}|$ is larger than $1+\mathrm{DQi}$, and keeps at the maximum reactive power QMAX after |Vi| exceeds VOP. DQi is defined as a turnup point to start compensating reactive power. The complete algorithm to determine $\mathrm{Pi}^{*}, \mathrm{Qi}^{*}$ is expressed as (1). As can be seen, parameters DPi and DQi determine the starting conditions to suppress voltage rise.

$$
\begin{gathered}
P_{i}^{*}=\left\{\begin{array}{cc}
P_{M P P T_{-} i} & ,\left|V_{i}\right|<1+D_{P i} \\
P_{M P P T_{-} i} \times \frac{V_{O P}-\left|V_{i}\right|}{V_{O P}-\left(1+D_{P i}\right)} & , 1+D_{P i} \leq\left|V_{i}\right|<V_{O P}, \\
0 & ,\left|V_{i}\right| \geq V_{O P}
\end{array}\right. \\
Q_{i}^{*}=\left\{\begin{array}{cc}
0 & ,\left|V_{i}\right|<1+D_{Q i} \\
Q_{M A X} \times \frac{\left|V_{i}\right|-\left(1+D_{Q i}\right)}{V_{O P}-\left(1+D_{Q i}\right)} & , 1+D_{Q i} \leq\left|V_{i}\right|<V_{O P} \\
Q_{M A X} & ,\left|V_{i}\right| \geq V_{O P}
\end{array}\right.
\end{gathered}
$$

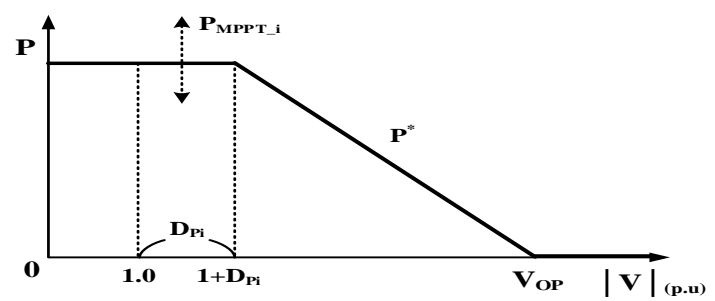

(a)

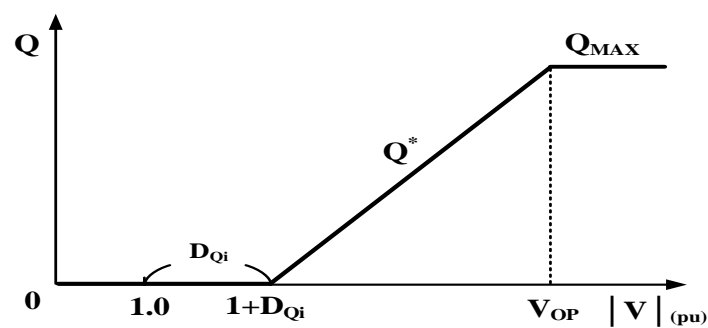

(b)
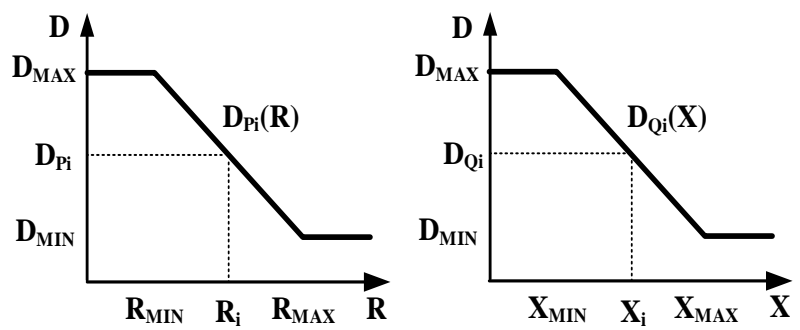

(c)

Fig.2. Determination of power command and droop relationship

(a) . real power control

(b). reactive power control

(c). DP-R and DQ-X droop 
In order to coordinate operation of dispersed PV inverters, DP-R and DQ-X droops are developed so that the starting points DPi, DQi of the inverters can be dynamically tuned according to resistance $\mathrm{Ri}$ and reactance $\mathrm{Xi}$ of the impedance $\mathrm{Zi}=\mathrm{Ri}+\mathrm{Xi}$ at installation location, respectively. Fig. 2c shows the proposed droop control. As can be seen, DPi is drooped by increasing Ri. High Ri results in low DPi. The inverter installed at high resistive point starts curtailing real power at lower $|\mathrm{Vi}|$ compared to the inverter installed at low resistive point. In contrast, DQi droops with increasing $\mathrm{Xi}$, which means that the inverter at higher reactance point starts compensating reactive power at lower $|\mathrm{Vi}|$. For example, both resistance and reactance at BUS3 are larger than those at BUS1 and BUS2 in Fig. 1a. Thus PV3 starts real power curtailment and reactive power compensation at lower voltage rise compared to PV1 and PV2 due to DP3 $<$ DP2 and DP3 <DP1.

The droop equations are expressed in (2). For simplicity, RMAX, XMAX and RMIN, XMIN are designed with the same value in this paper as given in (3). On the other hand, DMAX is less than VOP-1 to assure that PV inverter is able to terminate generation of real power when bus voltage is larger than VOP. The parameter DMIN is chosen based on the sensitivity of voltage fluctuation. PV inverter with smaller DMIN starts suppressing voltage rise at a lower voltage rise.

$$
\begin{gathered}
D_{P i}=\left\{\begin{array}{cc}
D_{M A X} & , R_{i}<R_{M I N} \\
D_{M I N}+\left(\frac{D_{M A X}-D_{M I N}}{R_{M A X}-R_{M I N}}\right) \times\left(R_{M A X}-R_{i}\right) & R_{M I N} \leq R_{i} \leq R_{M A X} \\
D_{M I N} & , R_{i}>R_{M A X}
\end{array}\right. \\
D_{Q i}=\left\{\begin{array}{cc}
D_{M A X} & , X_{i}<X_{M I N} \\
D_{M I N}+\left(\frac{D_{M A X}-D_{M I N}}{X_{M A X}-X_{M I N}}\right) \times\left(X_{M A X}-X_{i}\right) & , X_{M I N} \leq X_{i} \leq X_{M A X} \\
D_{M I N} & , X_{i}>X_{M A X}
\end{array}\right.
\end{gathered}
$$

$$
\begin{gathered}
R_{M A X}=X_{M A X}, R_{M I N}=X_{M I N} \\
D_{M A X}<V_{O P}-1
\end{gathered}
$$

\section{B. Power Calculation}

The output power of the inverter is calculated based on the so-called instantaneous reactive power theory [19]. As shown in (4), voltages and currents are transferred from the three-phase system to the stationary reference frame. Then both real power and reactive power Pi, Qi can be obtained by (5).

$$
\begin{aligned}
& {\left[\begin{array}{l}
v_{q s_{-} i} \\
v_{d s_{-} i}
\end{array}\right]=\left[\begin{array}{lll}
\frac{2}{3} & -\frac{1}{3} & -\frac{1}{3} \\
0 & -\frac{1}{\sqrt{3}} & -\frac{1}{\sqrt{3}}
\end{array}\right]\left[\begin{array}{l}
v_{a_{-} i} \\
v_{b_{-} i} \\
v_{c_{-} i}
\end{array}\right]} \\
& {\left[\begin{array}{l}
i_{q s_{-} i} \\
i_{d s_{-} i}
\end{array}\right]=\left[\begin{array}{lll}
\frac{2}{3} & -\frac{1}{3} & -\frac{1}{3} \\
0 & -\frac{1}{\sqrt{3}} & -\frac{1}{\sqrt{3}}
\end{array}\right]\left[\begin{array}{l}
i_{a_{-} i} \\
i_{b_{-} i} \\
i_{c_{-} i}
\end{array}\right]}
\end{aligned}
$$

$$
\begin{gathered}
P_{i}=\left[\left(v_{q s_{-} i} \times i_{q s_{-} i}\right)+\left(v_{d s_{-} i} \times i_{d s_{-} i}\right)\right] \\
Q_{i}=\left[-\left(v_{q s_{-} i} \times i_{d s_{-} i}\right)+\left(v_{d s_{-} i} \times i_{q s_{-} i}\right)\right]
\end{gathered}
$$

\section{Voltage Calculation}

Voltage magnitude $|\mathrm{Vi}|$ is calculated in the synchronous reference frame. As given in (6), voltages and currents are transferred from the stationary reference frame to the synchronous reference frame. Grid voltage angle $\theta$ _e is evaluated by using phase-locked-loop (PLL) as shown in Fig. 3a. The PI controller is applied to regulate the phase angle $\theta$ _e to achieve zero steadystate error between vde and vde*. Note that vde* is set as 0 and the feedforward term $\omega \mathrm{ff}$ is set as the nominal value of grid frequency. Fig. $3 b$ shows the per-unit transformation block diagram. The LPF filters are used to filter out ripple components in the calculation. Voltage magnitude $|\mathrm{Vi}|$ in per unit can be obtained by dividing the calculated grid voltage with the base voltage Vbase.

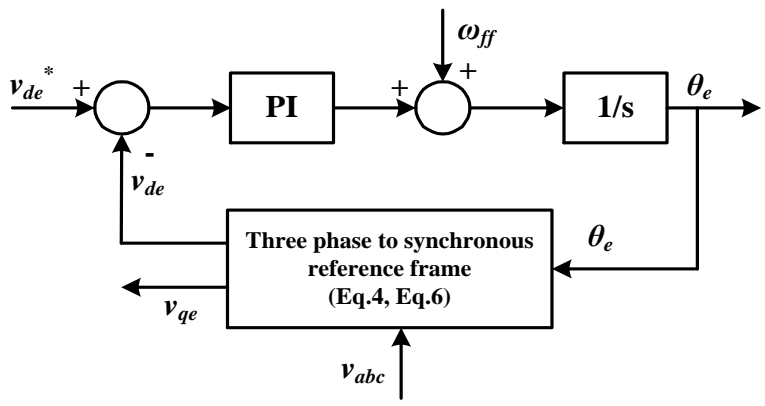

(a)

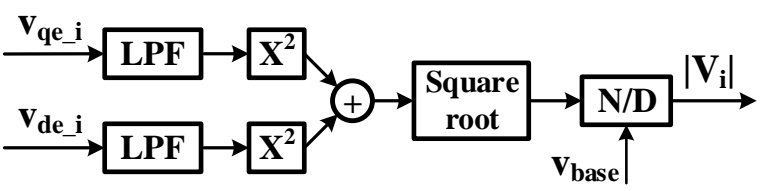

(b)

Fig.3.Block diagrams of the applied per-unit transformation

(a). phase-locked-loop block diagram

(b). per-unit transformation block diagram

$$
\begin{gathered}
{\left[\begin{array}{l}
v_{q e_{-} i} \\
v_{d e_{-} i}
\end{array}\right]=\left[\begin{array}{lc}
\cos \left(\theta_{e}\right) & -\sin \left(\theta_{e}\right) \\
\sin \left(\theta_{e}\right) & \cos \left(\theta_{e}\right)
\end{array}\right]\left[\begin{array}{l}
v_{q s_{-} i} \\
v_{d s_{-} i}
\end{array}\right]} \\
{\left[\begin{array}{l}
i_{q e_{-} i} \\
i_{d e_{-} i}
\end{array}\right]=\left[\begin{array}{cc}
\cos \left(\theta_{e}\right) & -\sin \left(\theta_{e}\right) \\
\sin \left(\theta_{e}\right) & \cos \left(\theta_{e}\right)
\end{array}\right]\left[\begin{array}{l}
i_{q s_{-} i} \\
i_{d s_{-} i}
\end{array}\right]}
\end{gathered}
$$

\section{Current control}

According to power commands Pi*, Qi*, two PI controllers are proposed to regulate output powers $\mathrm{Pi}, \mathrm{Qi}$, thus generating the current command of the inverter iqs*, ids*. In this paper, predictive current control is used to determine the voltage command vabc*[21]-[23]. The following PWM is to synthesize the control signals for all switches of the inverter to achieve the required power output. 


\section{SIMULATION STUDIES}

Fig. 1a and Table 1 show considered circuit and parameters in this section. Power-flow analysis and timedomain simulations are conducted to verify the effectiveness of the proposed control.

\section{A Power Flow Analysis}

Fig. 4 gives the flow chart to determine feeder voltage of Fig. 1a. Initially, bus voltages are derived assuming all inverters operated at MPPT mode. The proposed control in (1) is applied to find power command Pi*(n), Qi*(n). Then output power Pi(n), Qi(n) are updated by (7) in an iterative manner, where $n$ represents iteration number. Note that a convergence factor $\mathrm{K}$ in (7) is needed to assure convergence in the calculation. Bus voltages are found by resolving power flow equations using Newton-Raphson method. In order to evaluate functionality of the proposed control, three feeders with different parameters are considered, including rural, inductive and resistive feeders. Note that magnitude of feeder impedance is assumed equal for three cases.

Table 1 System parameters

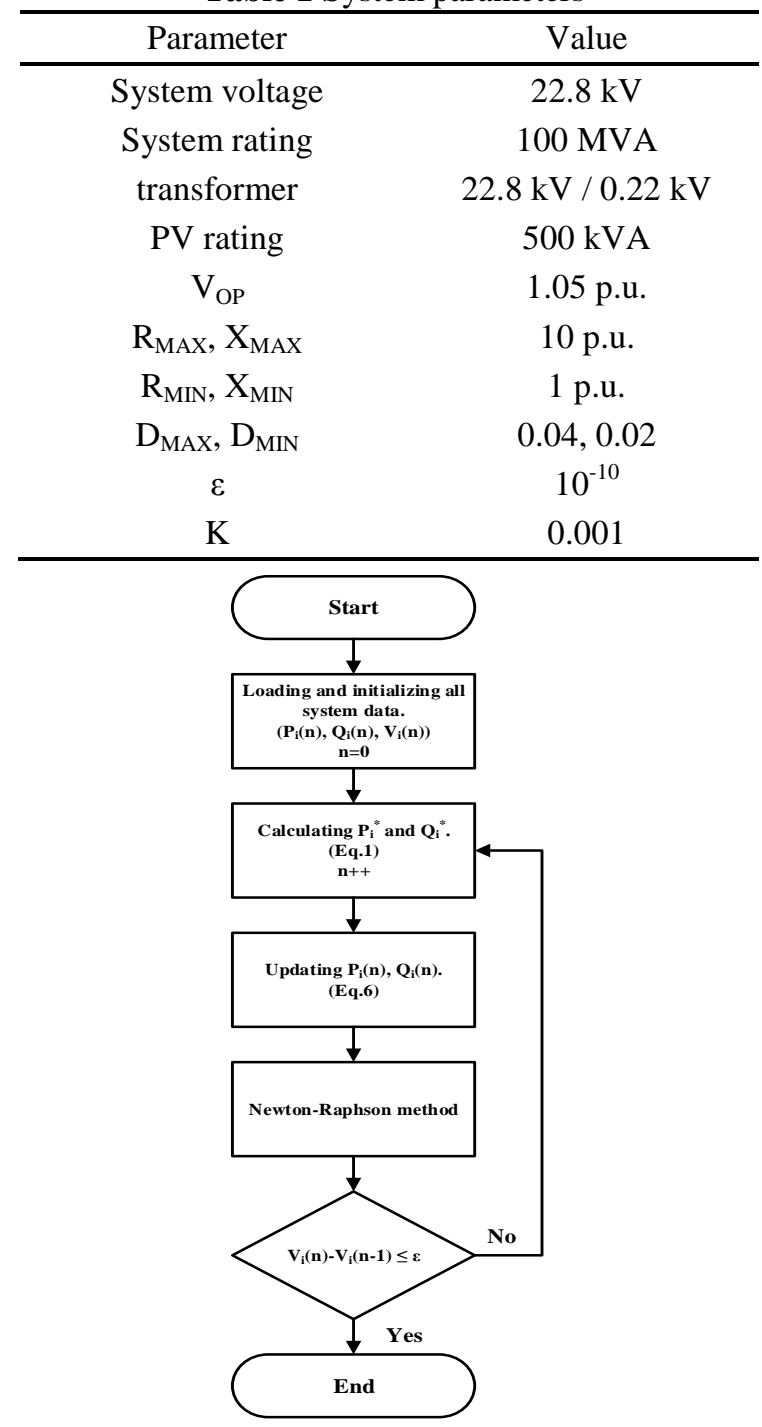

Fig. 2. Flow chart to determine operating point of PV inverter
Table 2 Simulation results for a rural feeder (a)Parameters

\begin{tabular}{c|c|c|c|c|c}
\hline \multicolumn{2}{c}{ Feeder Value (p.u) } & \multicolumn{3}{c}{$2.2+\mathrm{j} 2.856$} \\
\hline DP1 & DP2 & DP3 & DQ1 & DQ2 & DQ3 \\
0.0373 & 0.0324 & 0.0276 & 0.0359 & 0.0295 & 0.0232 \\
\hline
\end{tabular}

(b)Bus voltages and output power of the inverters in MPPT control

\begin{tabular}{|c|c|c|c|c|}
\hline \multirow{2}{*}{$\begin{array}{l}\text { Bus } \\
\text { No. }\end{array}$} & \multirow{2}{*}{$\begin{array}{c}\text { Voltage } \\
\text { Mag. (p.u) }\end{array}$} & \multirow{2}{*}{$\begin{array}{c}\text { Angle } \\
\text { Degree. }\end{array}$} & \multicolumn{2}{|c|}{ PV Generation } \\
\hline & & & MW & MVar \\
\hline - & 1.000000 & 0.000 & $\begin{array}{c}- \\
1.430593\end{array}$ & 0.090279 \\
\hline 1 & 1.029766 & 2.384 & 0.500000 & 0.000000 \\
\hline 2 & 1.045008 & 3.898 & 0.500000 & 0.000000 \\
\hline 3 & 1.060370 & 4.633 & 0.500000 & 0.000000 \\
\hline \multicolumn{2}{|c|}{ Total line loss } & & \multicolumn{2}{|c|}{0.069407} \\
\hline
\end{tabular}

(c)Bus voltages and output power of the inverters in the proposed control

\begin{tabular}{ccccc}
\hline \multirow{2}{*}{$\begin{array}{c}\text { Bus } \\
\text { No. }\end{array}$} & Voltage & Angle & \multicolumn{2}{c}{ PV Generation } \\
\cline { 4 - 5 } & Mag. (p) & Degree. & MW & MVar \\
\hline- & 1.000000 & 0.000 & - & 0.321437 \\
1 & 1.020454 & 2.379 & 0.500000 & 0.000000 \\
2 & 1.031490 & 3.915 & 0.499926 & 0.047860 \\
3 & 1.033701 & 4.635 & 0.363052 & 0.196079 \\
\hline \multicolumn{3}{c}{ Total line loss } & \multicolumn{3}{c}{0.059698} \\
\hline
\end{tabular}

$$
\begin{aligned}
P_{i}(n) & =P_{i}(n-1)+K \times\left(P_{i}{ }^{*}(n)-P_{i}(n-1)\right) \\
Q_{i}(n) & =Q_{i}(n-1)+K \times\left(Q_{i}{ }^{*}(n)-Q_{i}(n-1)\right)
\end{aligned}
$$

Table 2(a) lists the considered rural feeder with impedance $2.2+\mathrm{j} 2.856 \mathrm{pu}$. As can be seen, in this setup, both resistive and inductive parts of the feeder are dominant. Table 2(b) shows bus voltages when all PV inverters operate at MPPT mode outputting the rated real power $500 \mathrm{~kW}$. As shown, total real power $1.5 \mathrm{MW}$ supplied by three PVs results in significant voltage rise along the feeder. Since the voltage at bus 3 exceeds 1.06 pu, PV3 should disconnect from the grid. Thus total $1.0 \mathrm{MW}$ is generated by PV1 and PV2 running in MPPT mode. In the proposed control, both PV2 and PV3 reduce their real power and compensate reactive power. As shown in Table 2(c), all bus voltages are reduced below $1.05 \mathrm{pu}$. PV inverters with the proposed control are able to maintain bus voltages within the limit and boost total output power from to $1.3 \mathrm{MW}$. 
Table 3 Simulation results for an inductive feeder (a) Parameters

\begin{tabular}{c|c|c|c|c|c}
\hline \multicolumn{3}{c}{ Feeder Value (p.u) } & \multicolumn{3}{c}{$0.866+\mathrm{j} 3.5$} \\
\hline DP1 & DP2 & DP3 & DQ1 & DQ2 & DQ3 \\
0.0400 & 0.0384 & 0.0364 & 0.0344 & 0.0267 & 0.0200 \\
\hline
\end{tabular}

(b)Bus voltages and output power of the inverters in MPPT control

\begin{tabular}{ccccc}
\hline \multirow{2}{*}{$\begin{array}{c}\text { Bus } \\
\text { No. }\end{array}$} & Voltage & Angle & \multicolumn{2}{c}{ PV Generation } \\
\cline { 4 - 5 } \cline { 4 - 5 } Mag. (p) & Degree. & MW & MVar \\
\hline & 1.000000 & 0.000 & - & 0.117947 \\
1 & 1.009964 & 2.980 & 0.500000 & 0.000000 \\
2 & 1.017582 & 4.931 & 0.500000 & 0.000000 \\
3 & 1.021676 & 5.896 & 0.500000 & 0.000000 \\
\hline \multicolumn{3}{c}{ Total line loss } & \multicolumn{3}{c}{0.029141} \\
\hline
\end{tabular}

(c)Bus voltages and output power of the inverters in the proposed control

\begin{tabular}{ccccc}
\hline \multirow{2}{*}{$\begin{array}{c}\text { Bus } \\
\text { No. }\end{array}$} & Voltage & Angle & \multicolumn{2}{c}{ PV Generation } \\
\cline { 4 - 5 } & Mag. (p.u) & Degree. & MW & MVar \\
\hline- & 1.000000 & 0.000 & - & 0.128660 \\
1 & 1.009604 & 2.986 & 0.500000 & 0.000000 \\
2 & 1.016870 & 4.944 & 0.500000 & 0.000000 \\
3 & 1.020615 & 5.916 & 0.500000 & 0.010253 \\
\hline \multicolumn{3}{c}{ Total line loss } & \multicolumn{3}{c}{0.029297} \\
\hline
\end{tabular}

In the following, inductive feeder with impedance $0.866+\mathrm{j} 3.5 \mathrm{pu}$ is considered. Table 3(a) gives the feeder parameters and the corresponding droop setup. Table 3(b) shows bus voltages and inverter powers for inductive feeder. As shown, voltage rise is slight and less than DP1,DP2,DP3, so all PV inverters are able to operate in MPPT mode in this case. As expected, Table 3(c) shows that the proposed control does not change inverter operation. Note that PV3 compensates reactive power $0.01 \mathrm{MVar}$ because voltage at BUS3 is slightly larger than 1+DQ3 pu.

Table 4(a) shows the considered resistive feeder with impedance $3.5+\mathrm{j} 0.866 \mathrm{pu}$. In this case, voltage rise is significant due to injection of real power. Table 4(b) shows that voltages at BUS2, BUS3 exceed 1.08, 1.09 $\mathrm{pu}$, respectively. In this situation, both PV2 and PV3 have to stop operation. After the proposed control is enabled, Table 4(c) shows that voltage rise is clearly suppressed. Voltages at BUS1, BUS2, and BUS3 are reduced to $1.028 \mathrm{pu}, 1.039 \mathrm{pu}, 1.041 \mathrm{pu}$, respectively. PV2 and PV3 generate 0.24MW, 0.02MVar and $0.14 \mathrm{MW}, 0.19 \mathrm{MV}$ ar, respectively. PV1 still operates in MPPT mode with $0.5 \mathrm{MW}$ output. Therefore, the proposed control allows PV inverters to deliver more real power without exceeding the voltage limit in the resistive feeder.
Table 4 Simulation results for a resistive feeder (a) Parameters

\begin{tabular}{c|c|c|c|c|c}
\hline \multicolumn{2}{c}{ Feeder Value (p.u) } & \multicolumn{3}{c}{$3.5+\mathrm{j} 0.866$} \\
\hline DP1 & DP2 & DP3 & DQ1 & DQ2 & DQ3 \\
0.0344 & 0.0267 & 0.0200 & 0.0400 & 0.0384 & 0.0364 \\
\hline
\end{tabular}

(b)Bus voltages and output power of the inverters in MPPT control

\begin{tabular}{ccccc}
\hline \multirow{2}{*}{$\begin{array}{c}\text { Bus } \\
\text { No. }\end{array}$} & Voltage & Angle & \multicolumn{2}{c}{ PV Generation } \\
\cline { 4 - 5 } \cline { 4 - 5 } Mag. (p.u) & Degree. & MW & MVar \\
\hline 1 & 1.000000 & 0.000 & -1.395693 & 0.025874 \\
2 & 1.048683 & 0.710 & 0.500000 & 0.000000 \\
3 & 1.080786 & 1.148 & 0.500000 & 0.000000 \\
\hline \multicolumn{3}{r}{ Total line loss } & \multicolumn{3}{c}{0.104307} \\
\hline
\end{tabular}

(c)Bus voltages and output power of theinverters in the proposed control

\begin{tabular}{ccccc}
\hline \multirow{2}{*}{$\begin{array}{c}\text { Bus } \\
\text { No. }\end{array}$} & Voltage & \multirow{2}{*}{ Mag. (p.u) } & Degree. & MV Generation \\
\cline { 4 - 5 } \cline { 4 - 5 } & 1.000000 & 0.000 & -0.845135 & 0.218525 \\
1 & 1.027796 & 0.834 & 0.499950 & 0.000024 \\
2 & 1.038725 & 1.405 & 0.241670 & 0.015295 \\
3 & 1.041718 & 1.829 & 0.138090 & 0.194650 \\
\hline \multicolumn{3}{c}{ Total line loss } & \multicolumn{3}{c}{0.034575} \\
\hline
\end{tabular}

\section{B Time-Domain Simulation}

Fig. 5 shows time-domain simulation for the rural feeder. PV1, PV2, PV3 start in operation at $0.5 \mathrm{~s}, 1 \mathrm{~s}, 1.5 \mathrm{~s}$, respectively. In Fig. 5a, three PVs are operated in MPPT mode with output power 500MW for each inverter. As shown, bus voltages rise up after PV inverters are started one by one. Especially voltage at BUS3 approaches 1.06 pu. In Fig. 5b, PV inverters with the proposed control are simulated. As shown, real power is reduced and reactive power is increased, so that voltage rise is able to be effectively mitigated below $1.05 \mathrm{pu}$. Voltage at BUS3 is reduced from $1.06 \mathrm{pu}$ to $1.027 \mathrm{pu}$. Since PV3 is located at the end of the feeder, it curtails much more real power and compensates much more reactive power in order to reduce voltage rise compared with PV1 and PV2.

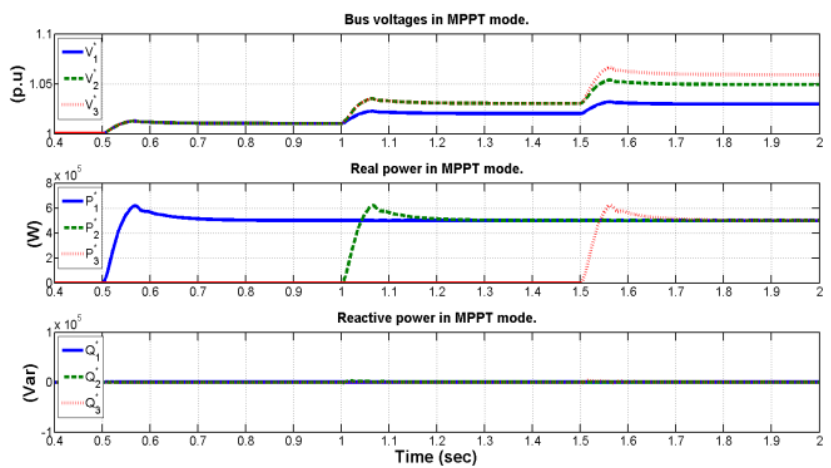

(a)

Fig.5. Bus voltages and PVs output power 


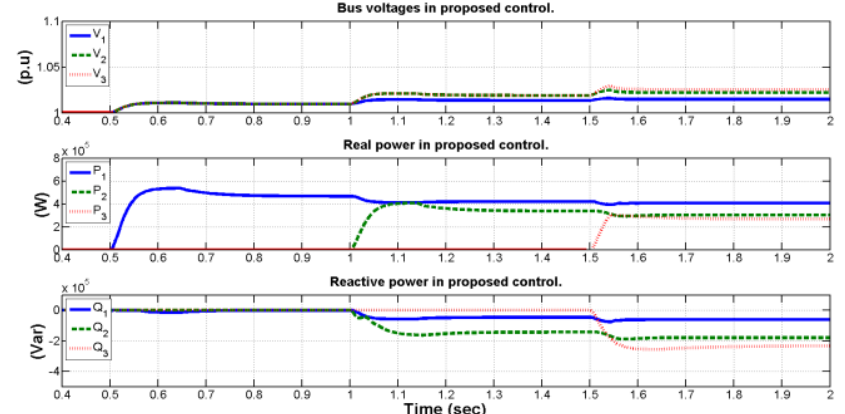

(b)

Fig. 3. Bus voltages and PVs output power

(a). All PVs are operated in MPPT mode

(b). All PVs are operated in the proposed control

\section{Power Fluctuation Study}

Fig. 6a gives PV generation from 6:00 AM to 18:00 PM in MPPT mode. Fig. 6b shows that voltage at BUS3 is beyond 1.05pu in day time from 10:00 AM and 12:00 AM. That means PV3 must stop operation during this time interval. The proposed control only comes in action from 10:00 to 14:00. Fig. 6c indicates that bus voltages can be well maintained below $1.05 \mathrm{pu}$ on all buses. Output power is significantly increased in this time frame as shown in Fig. 6d. For example, total power delivered to grid at $12: 00$ is $0.93 \mathrm{MW}$ in MPPT mode, which is less than $1.25 \mathrm{MW}$ in the proposed control. Note that output power of the proposed control is less than that of MPPT mode at 14:00. The reason is that the proposed control starts suppressing voltage rise even though voltage at BUS3 (1.046 pu) does not exceed the upper limit in MPPT mode.

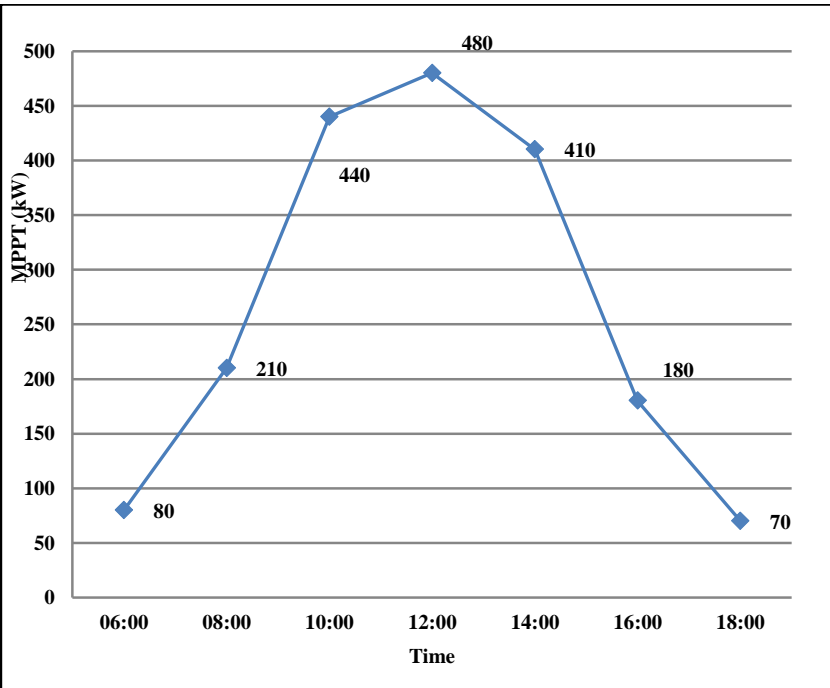

(a)

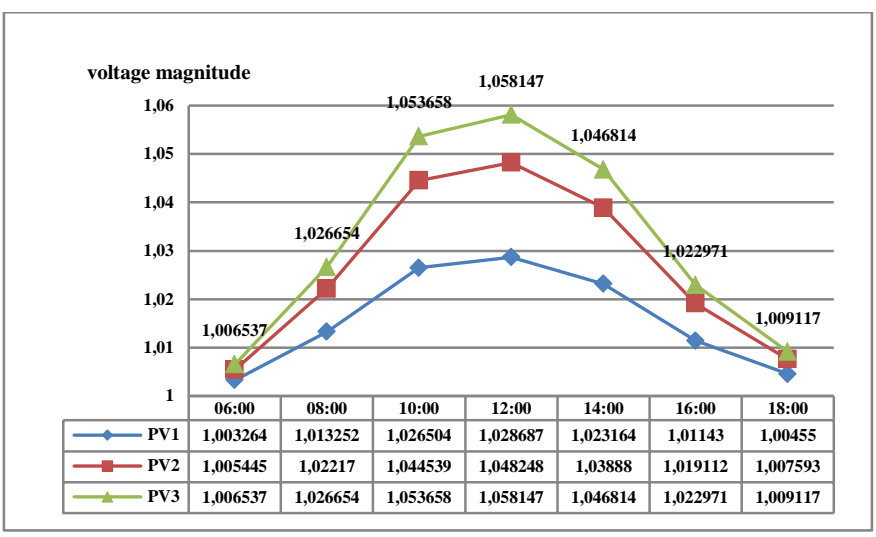

(b)

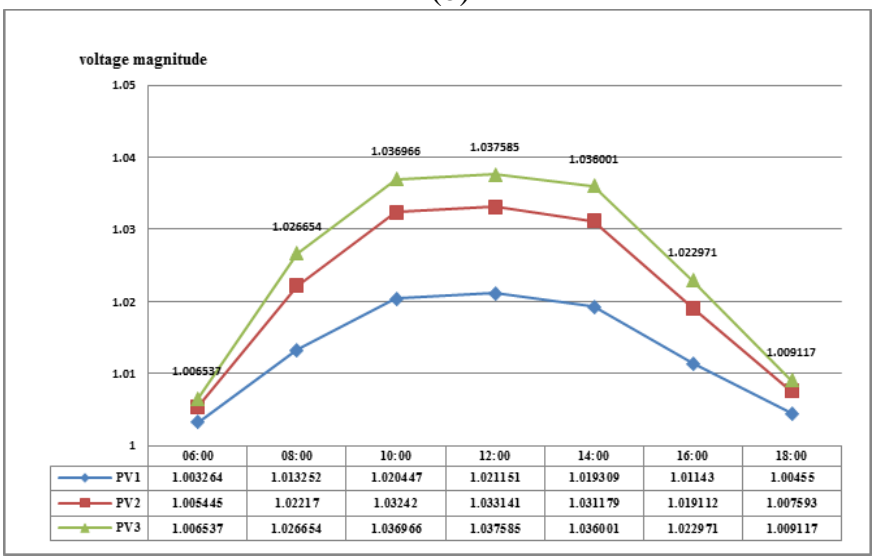

(c)

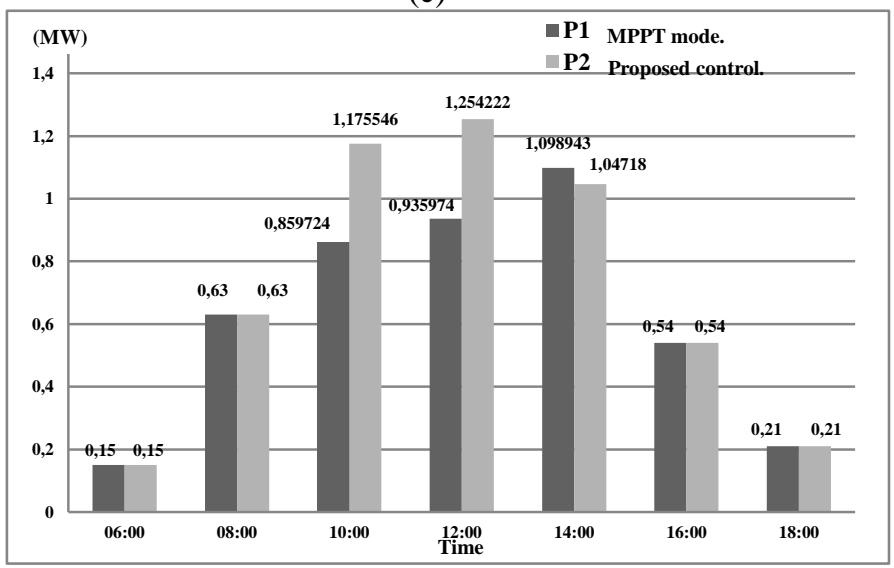

(d)

Fig. 4. Power fluctuation study

(a). PV output power from 6:00AM to 18:00PM in the MPPT mode

(b). Bus voltages in the MPPT mode

(c). Bus voltages in the proposed control

(d). Total supplied real power to grid with/without the proposed control

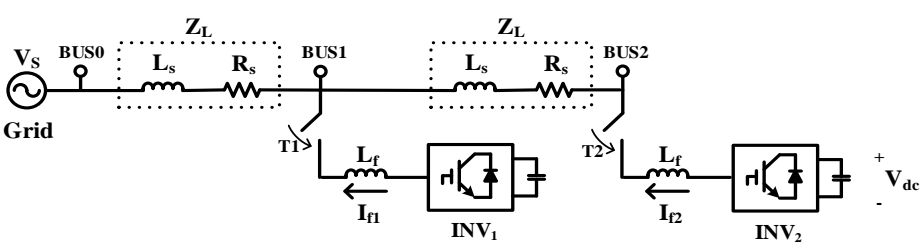

Fig. 5. Experimental circuit 
Table 5 Experimental Parameters

\begin{tabular}{|c|c|c|}
\hline Parameter & Symbol & Value \\
\hline $\begin{array}{l}\text { System } \\
\text { voltage }\end{array}$ & $\mathrm{V}_{\mathrm{s}}$ & $\begin{array}{l}\text { Three- } \\
\text { phase } \\
220 \mathrm{~V}\end{array}$ \\
\hline $\begin{array}{l}\text { System } \\
\text { rating }\end{array}$ & $\mathrm{S}_{\mathrm{s}}$ & $2 \mathrm{kVA}$ \\
\hline $\begin{array}{l}\text { Line } \\
\text { resistance }\end{array}$ & $\mathrm{R}_{\mathrm{s}}$ & $1 \Omega(4.1 \%)$ \\
\hline $\begin{array}{c}\text { Line } \\
\text { inductance }\end{array}$ & $\mathrm{L}_{\mathrm{s}}$ & $\begin{array}{c}1 \mathrm{mH} \\
(1.5 \%)\end{array}$ \\
\hline $\begin{array}{c}\text { Impedance at } \\
\text { bus } 1 \\
\left(\mathrm{R}_{1}+\mathrm{j} \mathrm{X}_{1}\right)\end{array}$ & $2.07+\mathrm{j} 0.78$ & $\mathrm{pu}$ \\
\hline $\begin{array}{c}\text { Impedance at } \\
\text { bus } 2 \\
\left(\mathrm{R}_{2}+\mathrm{j} \mathrm{X}_{2}\right)\end{array}$ & $4.13+j 1.56$ & $\mathrm{pu}$ \\
\hline $\begin{array}{l}\text { Inverter filter } \\
\text { inductor }\end{array}$ & $\mathrm{L}_{\mathrm{f}}$ & $5 \mathrm{mH}$ \\
\hline $\begin{array}{l}\text { Dc-link } \\
\text { voltage }\end{array}$ & $\mathrm{V}_{\mathrm{dc}}$ & $400 \mathrm{~V}$ \\
\hline $\begin{array}{l}\text { Upper limit } \\
\text { of voltage }\end{array}$ & $\mathrm{V}_{\mathrm{op}}$ & 1.05 \\
\hline $\begin{array}{c}\text { Impedance at } \\
\text { bus } 1 \\
\left(\mathrm{R}_{1}+\mathrm{j} \mathrm{X}_{1}\right)\end{array}$ & $\mathrm{V}_{\mathrm{s}}$ & $220 \mathrm{~V}$ \\
\hline
\end{tabular}

Table 6 Droop setup in the experiments

\begin{tabular}{|c|c|c|c|c|c|c|c|}
\hline \multicolumn{2}{|c|}{ Case } & \multicolumn{2}{|c|}{ (A) } & \multicolumn{2}{|c|}{ (B) } & \multicolumn{2}{|c|}{ (C) } \\
\hline \multicolumn{2}{|c|}{$\begin{array}{c}\mathrm{R}_{\text {MAX }}, \mathrm{X}_{\mathrm{MAX}} \\
\text { (p.u) }\end{array}$} & \multicolumn{2}{|c|}{2.5} & \multicolumn{2}{|c|}{2} & \multicolumn{2}{|c|}{2} \\
\hline \multicolumn{2}{|c|}{$\begin{array}{l}\mathrm{R}_{\mathrm{MIN}}, \mathrm{X}_{\mathrm{MIN}} \\
\text { (p.u) }\end{array}$} & \multicolumn{2}{|c|}{0.5} & \multicolumn{2}{|c|}{1.5} & \multicolumn{2}{|c|}{1.5} \\
\hline $\mathrm{D}_{\mathrm{MA}}$ & $\mathrm{D}_{\mathrm{MIN}}$ & 0.015 & 0.01 & 0.03 & 0.025 & 0.05 & 0.025 \\
\hline $\mathrm{D}_{\mathrm{P} 1}$ & $\mathrm{D}_{\mathrm{P} 2}$ & 0.0143 & 0.01 & 0.025 & 0.025 & 0.025 & 0.025 \\
\hline $\mathrm{D}_{\mathrm{Q} 1}$ & $\mathrm{D}_{\mathrm{Q} 2}$ & 0.0143 & 0.0124 & 0.03 & 0.0294 & 0.05 & 0.0471 \\
\hline
\end{tabular}

\section{EXPERIMENTAL RESULTS}

Fig. 7 and Table 5 show an established experimental circuit and the related parameters. For simplicity, two voltage-source inverters and three buses separated by line impedance are considered. Note that two inverters INV1, INV2 supply fixed output power $1 \mathrm{~kW}$ for each when working at MPPT mode. The inverters with the proposed DP-R and DQ- X droops are implemented to suppress voltage rise in a resistive feeder. Fig. 8 shows their output powers and corresponding voltage waveforms. Due to injection of the real power, $|\mathrm{V} 1|$ and $|\mathrm{V} 2|$ rise to 1.05 and $1.07 \mathrm{pu}$, respectively. Obviously, bus voltages exceed the upper limit when both inverters operate at MPPT mode with $1 \mathrm{~kW}$ output. Note that $|\mathrm{V} 0|$ is assumed as $1.0 \mathrm{pu}$.

In the following test, the inverters with different droop setup are evaluated. Table 6 gives considered droop parameters in three cases, in which parameters DP1, DP2, DQ1, DQ2 are determined according to feeder impedance R1, X1, R2, X2, respectively. Fig. 10a and $10 \mathrm{~b}$ show the power control in case (A). In this test, DP1, DP2, DQ1, DQ2 are designed to start voltage control at lower voltage rise compared with other cases. Due to DP1>DP2 and DQ1>DQ2, INV2 starts voltage control at lower voltage than INV1 does. Fig. 10c and 10d show output power and bus voltage. INV1, INV2 are started at T1, T2, respectively. As can be seen, |V1| and $|\mathrm{V} 2|$ are increased when INV1 starts at T1. INV1 curtails its real power and injects reactive power. At T2, INV2 starts in operation. INV2 supplies less real power than INV1 does, but INV2 compensates more reactive power than INV1 does. When reaching the steady state, bus voltages are well reduced below $1.05 \mathrm{pu}$ with curtailed power listed in Table 7.

In case (B), Fig. 11a and $11 \mathrm{~b}$ show that DP1, DP2, DQ1, DQ2 are increased to allow high voltage rise. Fig. 11c and 11d show that INV1 simple curtails its real power with no compensating reactive power. INV1 is able to supply more real power compared with case (A). The operation of INV2 is similar to that of INV2 in case (A). As expected, Fig. 11c and $11 \mathrm{~d}$ also show that bus voltages are slightly increased.

In case (C), Fig. 12a and 12b show both DQ1 and DQ2 are designed to approach VOP to avoid injection of reactive power. Both inverters simple curtails their real power and no reactive power is compensated. Fig. 12c and $12 \mathrm{~d}$ show that INV2 delivers less real power due to high |V2|. Since both inverters do not supply reactive power, voltage rise is significant compared with case (B).

Table 7 illustrates experimental results in all cases. We can see that bus voltages can be mitigated under VOP by the proposed control strategy. Curtailment of real power and compensation of reactive power are dependent on both feeder impedance and droop parameters. Case (A) shows that voltage rise is well suppressed on the entire feeder. Since power curtailment is started at low voltage rise, injected real power is significantly reduced. Raising the starting point DP1,DP2 can increase injection of real power as indicated in case (B). In case (C), both inverters do not compensate reactive power, resulting in serious voltage rise compared with other cases.

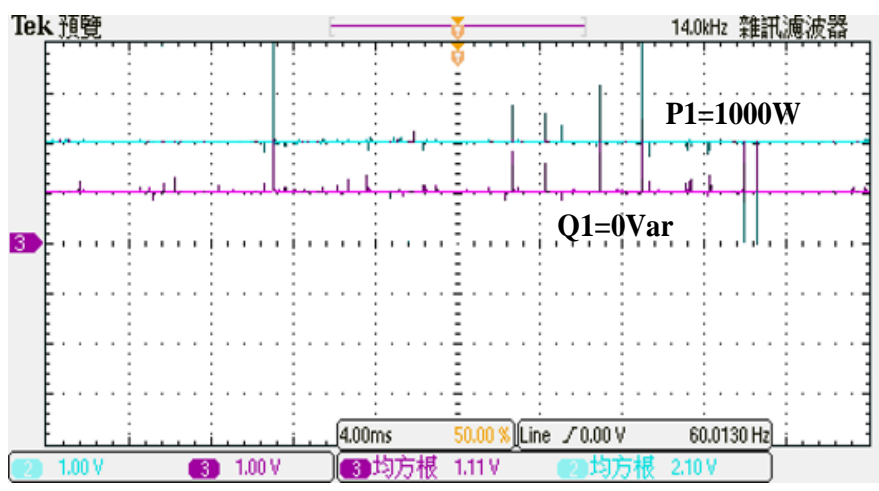

(a) 
Fig.6.Inverters output power and bus voltages (all inverters are operated in MPPT mode)

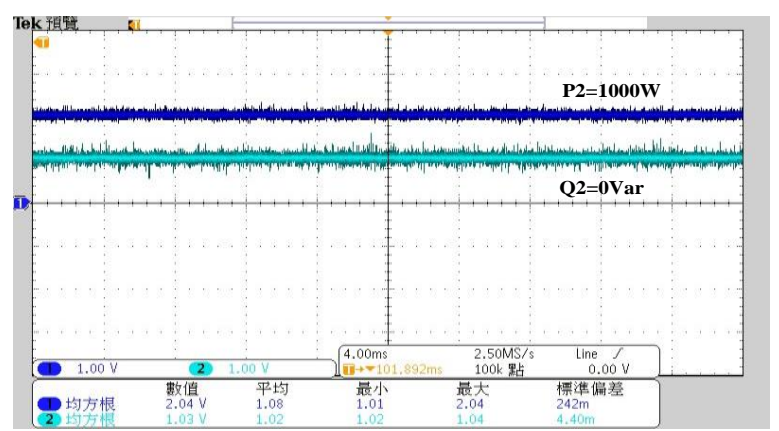

(b)

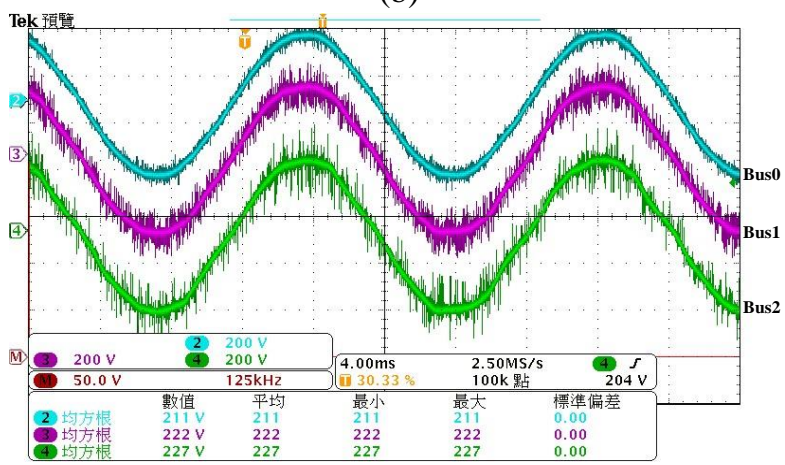

(c)

Fig. 7. Inverters output power and bus voltages (all inverters are operated in MPPT mode)
(a). The output power of INV 1
(b). The output power of $\mathrm{INV}_{2}$
(c). The a-phase voltages waveform and the corresponding rms value of three buses

Table 7 Bus voltages and Output power for three cases

\begin{tabular}{|c|c|c|c|}
\hline Case & (A) & (B) & (C) \\
\hline $\begin{array}{cc}\mathrm{P}_{1} & \mathrm{Q}_{1} \\
(\mathrm{~W}) & \text { (Var) }\end{array}$ & $680 \quad 240$ & 830 & 800 \\
\hline $\begin{array}{cc}\mathrm{P}_{2} & \mathrm{Q}_{2} \\
(\mathrm{~W}) & \text { (Var) }\end{array}$ & $460 \quad 500$ & $\begin{array}{cc}470 & 43 \\
& 0\end{array}$ & 360 \\
\hline $\mathrm{P}_{\text {total }}(\mathrm{W})$ & 1140 & 1300 & 1160 \\
\hline $\mathrm{Q}_{\text {total }}(\mathrm{Var})$ & 740 & 430 & 0 \\
\hline $\mathrm{V}_{1}(\mathrm{p} . \mathrm{u})$ & 1.0237 & 1.018 & 1.018 \\
\hline $\mathrm{V}_{2}(\mathrm{p} . \mathrm{u})$ & 1.0284 & 1.036 & 1.0405 \\
\hline
\end{tabular}

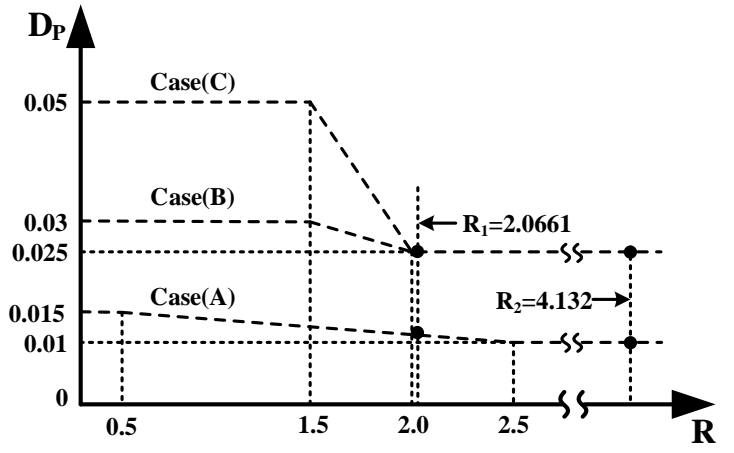

(a)

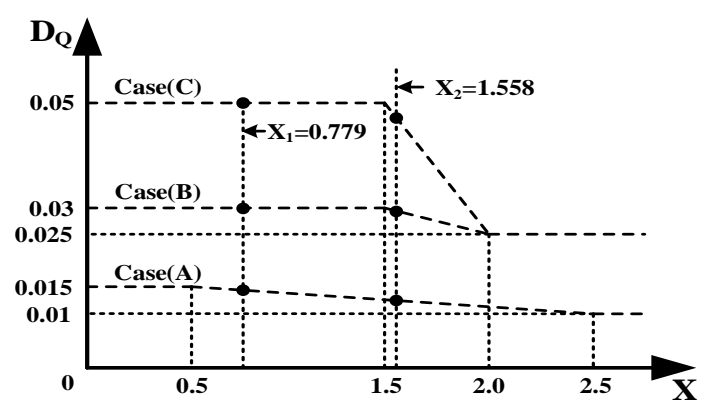

(b)

Fig. 8. $D_{P}$ and $D_{Q}$ setup
(a). $D_{P}$ droop setup in three cases
(b). $\mathrm{D}_{\mathrm{Q}}$ droop setup in three cases.

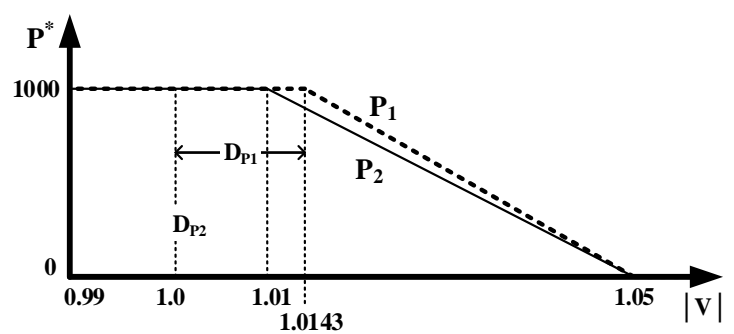

(a)

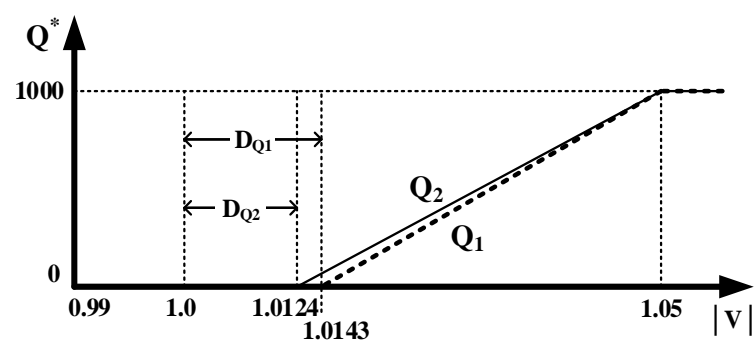

(b)

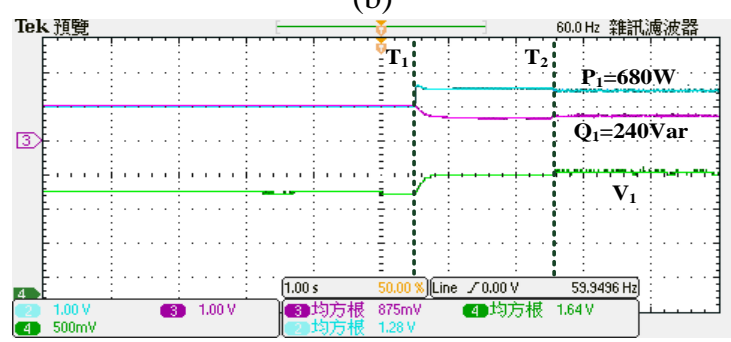

(c) 


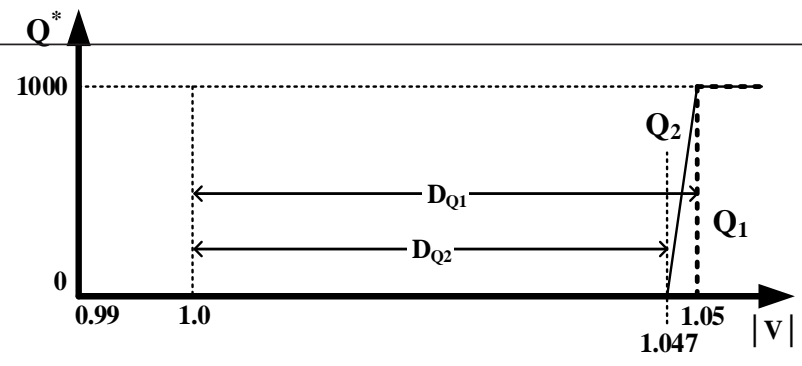

(b)

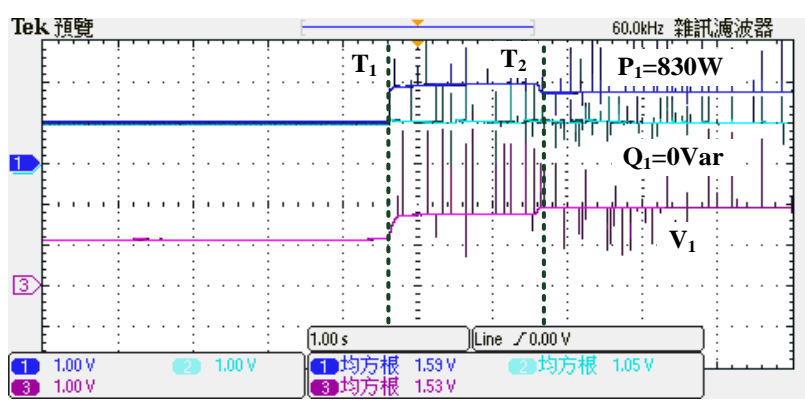

(c)

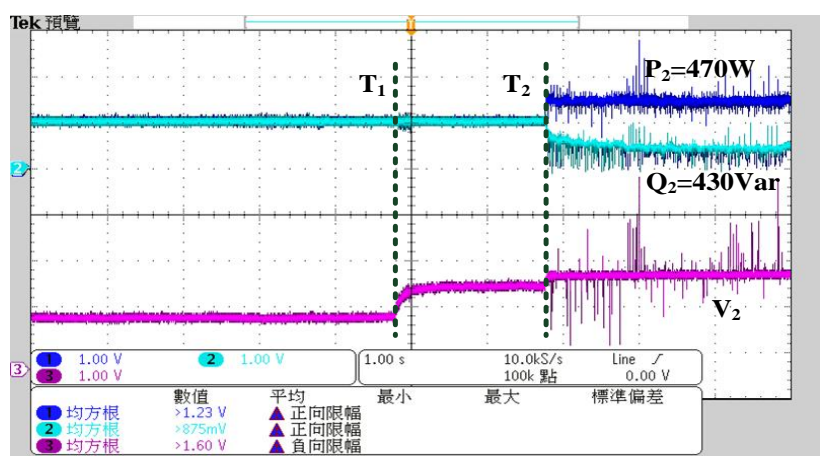

(c)

Fig. 10. Droop setup and output power of PV inverters in case (B)

(a). Real power control

(b). Reactive power control

(c). The output power of INV

(d). The output power of INV 2

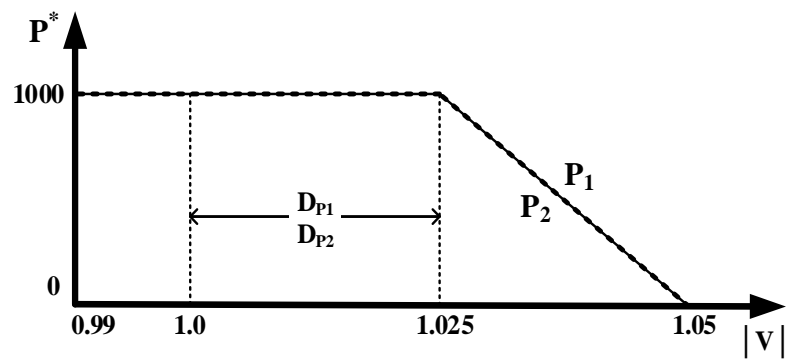

(a)

Fig. 11. Droop setup and output power of PV inverters in case $(\mathrm{C})$
(a). Real power control
(b). Reactive power control
(c). The output power of INV 1
(d). The output power of $\mathrm{INV}_{2}$

\section{CONCLUSION}


A decentralized control is presented for dispersed PV inverters to alleviate voltage rise in the distribution power system. The drooped characteristics are developed between the output power and the installation impedance so that the PV inverters are able to share workload of mitigating voltage rise based on their local voltage measurement. The inverter installed at high impedance node starts voltage control at low voltage rise. Reactive power compensation by inverters is able to suppress voltage rise in an inductive feeder, while curtailing real power can effectively mitigate voltage rise in a resistive feeder. Compared to conventional PV inverter, the proposed PV inverter is operated at neither MTTP mode nor unity power factor mode to assure feeder voltage within voltage upper limitation. The proposed control is verified by simulation studies, especially experimental results for a resistive feeder. As can be seen, the proposed method can avoid significant voltage rise at the end part of a long redial feeder with PV system installed. All PV inverters are able to supply power and suppress voltage rise in a cooperative manner, which could be a reasonable and/or justifiable solution for high penetration PV system.

\section{References}

1. Masters, C. L.: 'Voltage rise: The big issue when connecting embedded generation to long $11 \mathrm{kV}$ overhead lines,' Inst. Elect. Eng. Power Eng. J., 16, (1), pp. 5-12, (2002).

2. Sensarma, P. S., Padiyar, K. R. and Ramanarayanan, V.: 'Analysis and performance evaluation of a distribution STATCOM for compensating voltage fluctuations,' IEEE Trans. Power Del., 16, (2), pp. 259-264, (2001)

3. VDE-AR-N4105: 'Technical requirements for the connection to and parallel operation with low-voltage distribution networks', (2006).

4. IEC 61727: 'Photovoltaic (PV) SystemsCharacteristics of the Utility Interface', 2004.

5. Technical regulation on grid-connected operation for generation systems of renewable energy. TAIPOWER Company, (2006).

6. Gyugyi, L.: 'A unified power flow control concept for flexible ac transmission systems,' Proc. Inst. Elect. Eng., 139. (4), pp. 323-331, (1992)

7. Schauder, C., Gernhardt, M., Stacey, E., Lemak, T., Gyugyi, L., Cease, T., and Edris, A.: 'Development of a \pm 100 MVAr static condenser for voltage control of transmission systems,' IEEE Trans. Power Del., 10, (3), pp. 1486-1496, (1995)

8. Hingorani, N. G. and Gyugyi, L.: 'Understanding FACTS: Concepts and Technology of Flexible AC Transmission Systems' (Wiley-IEEE Press, 1999)

9. Akagi, H.: 'Active harmonic filters,' Proc. IEEE, 93, (12), pp. 2128-2141,( 2005)

10. Fujita, H. and Akagi, H.: 'Voltage-regulation performance of a shunt active filter intended for installation on a power distribution system,' IEEE
Trans. Power Electron., 22, (3), pp. 1046-1053, (2007)

11. Gupta, R., Ghosh, A., and Joshi, A.: 'Multiband hysteresis modulation and switching characterization for sliding-mode-controlled cascaded multilevel inverter,' IEEE Trans. Ind. Electron., 57, (7), pp. 2344-2353, (2010)

12. T. Lee, S. Hu, and Y. Chan.: 'D-STATCOM with positive-sequence admittance and negative-sequence conductance to mitigate voltage fluctuations in highlevel penetration of distributed-generation systems,' IEEE Trans. Ind. Electron., 60, (4), pp. 1417-1428, (2013)

13. Tonkoski, R., Lopes, L. A. C.: 'Voltage Regulation in Radial Distribution Feeders with High Penetration of Photovoltaic'. Energy 2030 Conference, 2008. ENERGY 2008. IEEE, Atlanta, U.S, pp. 1-7, (Nov 2008)

14. Braun, M.: 'Reactive power supply by distributed generators'. Power and Energy Society General Meeting - Conversion and Delivery of Electrical Energy in the 21st Century, 2008 IEEE, Pittsburgh, U.S, pp.1-8, (July 2008)

15. Braun, M., Stetz, T., Reimann, T., Valov, B. and Arnold, G.: 'Optimal reactive power supply in distribution networks-Technological and economic assessment for PV systems'. The 24th Eur. Photovoltaic Solar Energy Conf., Hamburg, Germany,( Sep 2009)

16. Backes, J., Schorn, C. and Basse, H.: 'Cost-efficient integration of dispersed generation using voltage dependent reactive power control'. The CIRED Workshop, Lyon, France, ( Jun 2010)

17. Demirok, E., Sera, D., Teodorescu, R. and Rodriguez, P.: 'Evaluation of the Voltage Support Strategies for the Low Voltage Grid Connected PV'. Energy Conversion Congress and Exposition 2010(ECCE), Atlanta, U.S, pp. 710-717,( Sep 2010)

18. Demirok, E., González, P. C., Frederiksen, K. H. B., Sera, D., Rodriguez, P. and Teodorescu, R.: 'Local Reactive Power Control Methods for Overvoltage Prevention of Distributed Solar Inverters in LowVoltage Grids', IEEE Journal of Photovoltaics, 1, (2), pp. 174-182, (2011)

19. Tonkoski, R., Lopes, L. A. C. and El-Fouly, T. H. M.: 'Coordinated active power curtailment of grid connected PV inverters for overvoltage prevention', IEEE Trans. Sustain. Energy, 2, (2), pp. 139-147, (2011)

20. T.L.Lee, S.S.Yang, S.H.Hu: 'Design of decentralized voltage control for PV inverters to mitigate voltage rise in distribution power system without communication', 2014 International Power Electronics Conference (IPEC-Hiroshima 2014 ECCE ASIA), Hiroshima, Japan, pp. 2606-2609, (May 2014)

21. Brod, David M., Novotny, Donald W.: 'Current Control of VSI-PWM Inverters', IEEE Trans. Ind. Applications., IA-21, (3), pp. 562-570, (1985) 
22. Habetler, T. G.: ' A space vector-based rectifier regulator for $\mathrm{AC} / \mathrm{DC} / \mathrm{AC}$ converters', IEEE Trans. Power Electron., 8, (1), pp. 30-36, (1993)

23. Jintakosonwit, P., Fujita, H., Akagi, H.: 'Control and performance of a fully-digital-controlled shunt active filter for installation on a power distribution system', IEEE Trans. Power Electron., 17, (1), pp. 132-140, (2002). 